\title{
Ancianos: relación entre residencia y estado de salud
}

\author{
Elderly: relationship between residence and health status
}

\author{
Soraia Azevedo ${ }^{1}$, Rosana Maia², Emilia Guerreiro² \\ ${ }^{1}$ ULSAM - Ponte de Lima, ${ }^{2}$ ULSAM - Viana do Castelo
}

\begin{abstract}
Introduction: The European population is aging, for every 100 young people there are 128 elderly. There is a decrease in the number of elderly people living in their family environment. The main objective of this study is to identify the differences in the general health status of the elderly according to their residence: in families or in others types of centres (nursing home, host family or national integrated network of integrated care (NINIC)).

Material and Methods: This is an observational study, using a sample of 254 elderly patients admitted to the Internal Medicine Service.

Results: Of the patients studied, 78,7\% lived at home/with relatives, $15,4 \%$ in nursing homes, 3,15\% in host families and 2,75\% in NINIC. Age ranged from 65 to 99 years, with a median of 80 years $(S D=7,97)$. Patients from their homes were more independent/mild dependence $(X(3)=59.8, p<0.001)$, although there were no significant differences in the number of comorbidities $(t(252)=0.029, p=0.999)$. However, patients from others centres had more neurological pathology $(X(1)=12.39, p<0.001)$. There were no statistically significant differences in the number of medications usually taken, although patients from others centres had more potentially inappropriate medications $(t(252)=5.85, p<0.001)$ and potential prescribing omissions $(t(252)=3.71$, $p<0.001)$. Patients at home had fewer rehosts $(X(1)=5.14, p=0.039)$. There were more intercurrences $(X(1)=19.0, p<0.001)$ and more deaths at 6 months after discharge $(X(1)=16.3, p<0.001)$ from others centres.
\end{abstract}

Conclusion: In a population less attended by families, these differences in relation to their dwelling places are paramount.

Keywords: Elderly; Nursing home; House; Health status; Host families.

\section{INTRODUCTION}

With the various changes in society, both socially and economically, there is a reduction in the number of elderly people living in their homes, leaving the family to be the main caretaker'. In 2011, about $19 \%$ of the population aged 65 or over (elderly). The aging rate of the population worsened to 128 (102 in 2001), which means that for every 100 young people there are 128 elderly people 2 .

Aging leads to the possibility of greater dependence, which is associated with increased costs and decreased quality of life. The Katz scale assesses the autonomy of the elderly to perform the basic and essential activities of daily life, called Basic Activities of Daily Living (BADLs) ${ }^{1}$.

The need for care is sensitive and influenced by moral and cultural aspects. Several studies have evaluated the preference of the elderly as to who cares for them. Despite all cultural and social differences, studies are consensual in the preference of the elderly for being cared for by relatives even when they are in palliative care ${ }^{3}$. But besides this preference being evidently influenced by affection and familiarity, this study intends to verify if are there differences in care. Does the type of caregivers, such as the house (home, nursing home; national integrated network of integrated care (NINIC) or host family) influence health status?

On the other hand, the elderly have more comorbidities and are more polymedicated, so they are more subject to iatrogenesis and inadequate prescriptions that include potentially inappropriate medications (PIM) and potential prescribing omissions (PPO), identified by the STOPP criteria (Screening Tool of Older Persons' Prescriptions) and START criteria (Screening Tool to Alert to Right Treatment) ${ }^{4,5}$.
Several studies proven the association between PIM and PPO with adverse pharmacological effects, hospitalizations, morbidity and mortality, functional disability and consequently associated with more costs ${ }^{6,7}$. Hence it is important to determine whether there are significant differences in the number and type of PIM and PPO according to the provenance of the patients. This study has as main objective to evaluate the differences between the provenances of the elderly that were hospitalized in the Internal Medicine Service and how the origin influences the basal state of health, the hospitalization and the evolution after discharge.

\section{MATERIAL AND METHODS}

A retrospective observational study was performed to evaluate the differences in health status according to the origin of the patients. The research protocol was approved by the Ethics Committee of the Unidade Local de Saúde do Alto Minho (ULSAM). Taking into account the 2011 census, the district of Viana do Castelo consists of 56,851 elderly people, 2 for a $95 \%$ confidence interval (calculated by Epiinfo $®$, version 7.2.1.0), the representative sample of the population of Viana includes 254 elderly people. Patients aged 65 or over who were admitted to the Internal Medicine Unit of ULSAM since January 1, 2019 to a total of 254 consecutive patients hospitalized in the beds under the responsibility of the authors, and hospitalization through the emergency service occurs randomly by the service. Patients in palliative care and in-hospital deaths were excluded because it was not possible to evaluate the PPO introduced, PIM suspended, rehospitalization and death within 6 months after discharge. 
The patients were separeted in two groups according to their residence: in families our in others types of centres (nursing home, host family or national integrated network of integrated care (NINIC).

There is no consensus on the definition of polymediction, but the value of 5 or more drugs is the most consensual, so this was the value assigned ${ }^{8}$.

The degree of dependence was assessed by the Katz scale before the acute phase, admission and discharge ${ }^{1}$.

Charlson index is a method of classifying comorbidity provides a simple, readily applicable and valid method of estimating risk of death from comorbid disease ${ }^{9}$.

The STOPP / START criteria were used to assess the PIM and PPO, but updated according to the latest recommendations. Particulary with regard to hypocoagulation in atrial fibrillation ${ }^{10}$, to the prescription of proton pump inhibitors ${ }^{11}$ and antipneumococcal vaccination ${ }^{12}$.

The classification of the professions was made by the Portuguese classification of the professions 2010. The evaluation of the number of outpatient consultations took into consideration only the consultations made by doctors. It was considered excessive alcohol consumption, if superior to the recommended one (up to $10 \mathrm{gr}, 20 \mathrm{gr}$ if man from 18 to 64 years); addiction was considered a psychiatric illness ${ }^{13}$.

\section{STATISTICAL ANALYSIS}

Statistical analysis was performed in the Statistical Package for Social Sciences (SPSS) version 24. The descriptive statistical analysis was performed by the evaluation of the absolute and relative frequencies of the categorical variables and by the calculation of the mean, median and standard deviation in the continuous variables. A Kolmogorov-Smirnov (KS) test was used to determine the distribution of continuous variables if the number of cases was greater than 50 and by the Shapiro-Wilk test (SW) if the number of cases was lower. In the comparison of means between groups, for the variables with normal distribution, the Student $t$ Test (t) was applied. The Mann-Whitney $U$ test (U), if the independent variable was binary, was applied to the normal independent variables with more than 3 categories, and the Kruskalwallis $H$ test $(\mathrm{H})$, in which case had more than 2 categories. In the case of dependent variables, the Wilcoxon test (W) was used. For the evaluation of the relationship between two categorical variables, the Chi-square test ( $x 2$ ) was used, and when its assumptions were not assured Fisher's Exact Test was used. To measure the degree of correlation between two quantitative variables Pearson's Correlation Coefficient was used. The value of statistical significance for all tests was defined as 2-sided $p<0.050$.

\section{RESULTS}

A total of 254 cases were evaluated and categorized according to their address in the domicile, home, host family and NICIC. Of the 254 cases, 200/254 live at home / with relatives (78.7\%), and 54/254 (21.3\%) in outher centres (39 in nursing homes (15.4\%), 8 (3.15\%) in host families and 7 (2.75\%) in NICIC (Graph 1)).

Graph 1. Distribution of cases according to provenance.

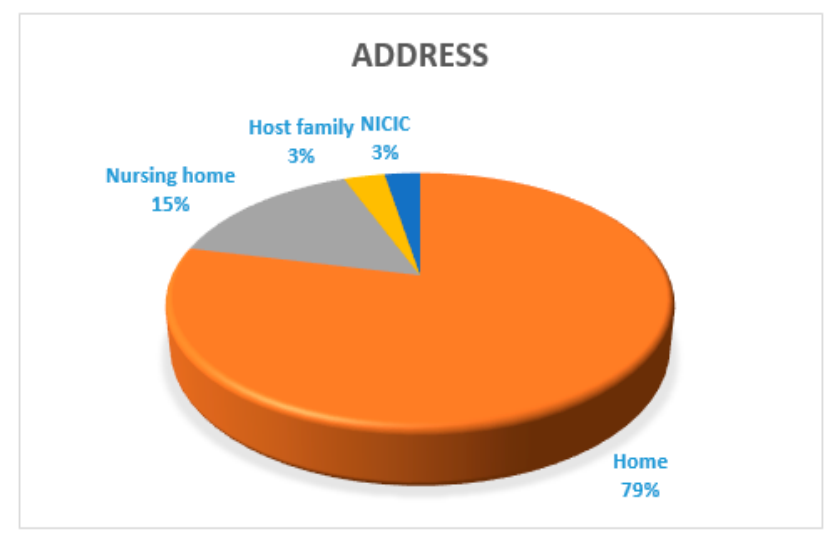

The age of the 254 cases ranged from 65 to 99 years, with a median of 80.0 years $(S D=7.97)$. There were no significant differences between the different sources $(\mathrm{t}(252)=1.84$, $p=0.067) .113$ cases were male (44.5\%) and 141 female $(55.5 \%)$, with no significant difference between the provenance $(X(1)=3.46, p=0.066)$.

There were no statistically significant differences between schooling (Fisher's exact test $=2.82, p=0.969$ and profession (Fisher's exact test $=11.9, p=0.100$ ) according to the provenance of the cases. Most of the cases were unskilled workers with 4 or less years of schooling (Table 1).

There are statistically significant differences between the degree of dependence according to the provenance of the patients $(X(3)=59.8, p<0.001)$. Patients from the home are more independent/slightly dependent, while those from others centres are more dependent.

There were no significant differences in the number of comorbidities ( $(252)=0.029, p=0.999)$ with all patients having at least a comorbidity with a maximum of 16 and a mean of $6.76(\mathrm{SD}=2.8)$. Despite this, the Charlson index was superior in patients from others centres than from families $(t(252)=5.24, p=0.002)$.

However there are differences regarding the type of comorbidities, others centres' patients have more neurological pathology $(X(1)=12.39, p<0.001)$.

The hospitalization led to a significant worsening of the degree of dependency in patients from the home $(Z=-5.16$, $p<0.001$ ) but not to patients from others centres (Table 2).

The number of drugs prescribed ranged from 0 to 19, with a mean of 7.7 ( $\mathrm{SD}=3.5$ ). A total of 1953 medications usually taken by 254 patients. There were no significant differences in the total number of drugs prescribed between the different origins ( $t(252)=0.66, p=0.610$ ). $81.9 \%$ of the cases were polymedicated and only $3(1.18 \%)$ of the patients had no 
Table 1. Classification of cases in relation to age, sex, schooling and profession.

\begin{tabular}{|c|c|c|c|}
\hline & Families & Other centres & Comparation \\
\hline Age (years) & $79.6(\mathrm{SD}=8.2)$ & $81.8(\mathrm{SD}=6.9)$ & $t(252)=1.84, p=0.067$ \\
\hline Sex & $\begin{array}{l}\text { Male: } 95 / 200(47.5 \%) \\
\text { Female: } 105 / 200(52.5 \%)\end{array}$ & $\begin{array}{l}\text { Male: } 18 / 54(33.3 \%) \\
\text { Female: } 36 / 54(66.7 \%)\end{array}$ & $X(1)=3.46, p=0.066$ \\
\hline \multicolumn{4}{|l|}{ Portuguese Classification of Professions } \\
\hline Professions of the Armed Forces & $5 / 200(2.50 \%)$ & 0/54 (0.00\%) & \multirow{11}{*}{$\begin{array}{l}\text { Fisher's exact test } \\
=11.9, p=0.100\end{array}$} \\
\hline $\begin{array}{l}\text { Representatives of the Legislative Power/Executive Bodies, } \\
\text { Officers, Directors, Executive Managers }\end{array}$ & 0/200 (0.00\%) & 0/54 (0.00\%) & \\
\hline Specialists in Intellectual and Scientific Activities & $2 / 200(1.00 \%)$ & $0 / 54(0.00 \%)$ & \\
\hline Technicians/Intermediate Professions & $0 / 200(0.00 \%)$ & $1 / 54(1.85 \%)$ & \\
\hline Administrative staff & $13 / 200(6.50 \%)$ & $1 / 54(1.85 \%)$ & \\
\hline Workers in Personal, Security and Safety Services and Sellers & $7 / 200(3.50 \%)$ & $4 / 54(7.41 \%)$ & \\
\hline Farmers and Skilled Workers in Agriculture, Fisheries and Forestry & 2/200 (1.00\%) & $0 / 54(0.00 \%)$ & \\
\hline Skilled Workers in Industry, Construction and Crafts & $34 / 200(17.0 \%)$ & 3/54 (5.55\%) & \\
\hline Plant and Machine Operators and Assembly Workers & $2 / 200(1.00 \%)$ & $1 / 54(1.85 \%)$ & \\
\hline Unskilled workers & $87 / 200(43.0 \%)$ & $24 / 54(44.4 \%)$ & \\
\hline Unknown & $48 / 200(24.0 \%)$ & $20 / 54(37.0 \%)$ & \\
\hline \multicolumn{4}{|l|}{ Education } \\
\hline Illiterate or $<4$ years of schooling & $52 / 200(26.0 \%)$ & 9/54 (16.7\%) & \multirow{7}{*}{$\begin{array}{l}\text { Fisher's exact test } \\
=2.82, p=0.969\end{array}$} \\
\hline 1st Cycle & $60 / 200(30.0 \%)$ & $14 / 54(24.9 \%)$ & \\
\hline 2nd Cycle & $5 / 200(2.50 \%)$ & $1 / 54$ (1.85\%) & \\
\hline 3rd Cycle & $2 / 200(1.00 \%)$ & $1 / 54(1.85 \%)$ & \\
\hline High school & $1 / 200(0.50 \%)$ & $0 / 54(0.00 \%)$ & \\
\hline Higher education & $4 / 200(2.00 \%)$ & $0 / 54(0.00 \%)$ & \\
\hline Unknown & $76 / 200$ (38.0\%) & $23 / 54$ (42.6\%) & \\
\hline
\end{tabular}

chronic medications. There were no significant differences between polimedication in the different origins $(X(1)=2.27$, $p=0.092)$. In spite of this, patients coming from others centres have significantly plus PIM ( $(252)=5.85, p<0.001)$ and PPO $(t(252)=3.71, p<0.001) .24 .8 \%$ of the 326 PIM were suspended and $17.2 \%$ of the 203 PPO were introduced. However, there were no statistically significant differences between the number of suspended PIM $(X(1)=1.73$, $p=0.217)$ or PPO introduced $(X(1)=2.31, p=0.156)$ according to the origin (Table 3).

In the cases from the home, $34.5 \%$ of the patients had no prescribed PIM, the number of PIM varied from 0 to 4 with a mean of 1.05 (SD=0.94), of the 209 PIM prescribed, 61 (29.2\%) were benzodiazepines, 56 (26.8\%) were proton pump inhibitors. The number of PPO ranged from 0 to 4 with a mean of $0.70(S D=0.78)$, of the 140 PPO prescribed were introduced $31(22.1 \%)$, the most frequent PPO was the antipneumococcal vaccine in 79 patients $(56.4 \%)$ followed by antireabsorption therapy in 13 patients (9.29\%).

In the others centres' cases, just one patent had no PIM, (98.1\% of patient had at leat one PIM). The number of PIM ranged from 1 to 5 with a mean of $2.19(\mathrm{SD}=1.18)$. Of the 118 PIM, 24 (20.3\%) were antipsychotic with no indi- cation, mainly due to its extrapyramidal lateral effects, 21 (17.8\%) were PPIs and 18 (15.6\%) were benzodiazepines. The number of PPO ranged from 0 to 3 with a mean of 1.17 (SD=0.97), of the 63 PP0 were introduced $9(14.3 \%)$, the most frequent PPO was vitamin D in 27 (42.9\%) of the cases, followed by $14(22.2 \%)$ the pneumococcal vaccine and 7 $(11.1 \%)$ antireabsorption therapy.

The days of hospitalization ranged from 1 to 46 days, with a mean of $10.7(S D=8.4)$ days. The number of days of hospitalization did not differ significantly according to the origin of the patients $(t(252)=6.9, p=0.301)$. Despite this, there are significant differences in the percentages of readmissions $(X(1)=5.14, p=0.039)$, with patients coming from home to be significantly less readmitted. There were no significant differences in the presence of hospitalizations prior to that included in this study $(X(1)=3.54, p=0.077)$. Patients from families had significantly less complications in hospitalization $(X(1)=19.0, p<0.001)$. Also in relation to death in less than 6 months after discharge there were statistically significant differences, patients from the home died significantly less $(X(1)=16.3, p<0.001)$, the overall death rate was $16.9 \%$ (Table 4). 
Table 2. Evaluation of the differences regarding the follow-up in outpatient care, degree of dependence / aggravation with hospitalization and comorbidities.

\begin{tabular}{|c|c|c|c|}
\hline Follow-up in External Consultation & Families & Other centres & Comparation \\
\hline No outpatient follow-up & $75 / 200(37.5 \%)$ & $26 / 54(48.1 \%)$ & \multirow{3}{*}{$X(6)=3.40, p=0.761$} \\
\hline An external consultation & $68 / 200(34.0 \%)$ & $17 / 54(31.5 \%)$ & \\
\hline Two or more external consultation & $57 / 200(28.5 \%)$ & $11 / 54(20.3 \%)$ & \\
\hline \multicolumn{4}{|l|}{ Degree of dependence prior to admission } \\
\hline Total dependency & $30 / 200(15.0 \%)$ & $33 / 54(61.1 \%)$ & \multirow{4}{*}{$\underline{X(3)=59.8, p<0.001}$} \\
\hline Moderate to severe dependence & $54 / 200(27.0 \%)$ & $17 / 54(31.5 \%)$ & \\
\hline Light dependence & $22 / 200(11.0 \%)$ & $1 / 54(1.85 \%)$ & \\
\hline Independence & $94 / 200(47.0 \%)$ & $3 / 54(5.55 \%)$ & \\
\hline Aggravation of dependence on hospitalization & $Z=-5,16, p<0,001$ & $Z=-0,91, p=0,362$ & \\
\hline Number of comorbilities & $6.76(\mathrm{SD}=2.8)$ & $6.76(\mathrm{SD}=2.8)$ & $\mathrm{t}(252)=0.029, \mathrm{p}=0.999$ \\
\hline Charlson index & $5.84(\mathrm{SD}=1.9)$ & $6.7(\mathrm{SD}=1.4)$ & $\underline{\mathrm{t}(252)=5.24, \mathrm{p}=0.002}$ \\
\hline \multicolumn{4}{|l|}{ Type of comorbidity } \\
\hline Neurological pathology & $82 / 200(41.0 \%)$ & $37 / 54(68.5 \%)$ & $\underline{X(1)=12.39, p<0.001}$ \\
\hline Obesity / Overweight & $58 / 200(29.0 \%)$ & 10/54 (18.5\%) & $X(1)=2.38, p=0.123$ \\
\hline Arterial hypertension & 155/200 (77.5\%) & 40/54 (74.1\%) & $X(1)=0.28, p=0.717$ \\
\hline Diabetes Melittus Type 2 & $77 / 200(38.5 \%)$ & $20 / 54(37.0 \%)$ & $X(1)=0.32, p=0.902$ \\
\hline Dyslipidemia & $110 / 200$ (55.0\%) & $33 / 54(61.1 \%)$ & $X(1)=0.65, p=0.444$ \\
\hline Excessive consumption of alcohol & $18 / 200(9.00 \%)$ & $2 / 54(3.70 \%)$ & $X(1)=1.69, p=0.262$ \\
\hline Smoking (ex-smoker or smoker) & $39 / 200(19.5 \%)$ & $4 / 54(7.41 \%)$ & $X(1)=5.03, p=0.081$ \\
\hline Pulmonary disease & $63 / 200(31.5 \%)$ & $13 / 54(24.1 \%)$ & $X(1)=1.11, p=0.320$ \\
\hline Cardiac pathology & $109 / 200$ (54.5\%) & $37 / 54(68.5 \%)$ & $X(1)=3.42, p=0.087$ \\
\hline Hematologic pathology & $40 / 200(20.0 \%)$ & $14 / 54(25.9 \%)$ & $X(1)=1.46, p=0.252$ \\
\hline Psychiatric Pathology & $57 / 200(28.5 \%)$ & $14 / 54(25.9 \%)$ & $X(1)=0.14, p=0.708$ \\
\hline Malignant neoplasm & $46 / 200(23.0 \%)$ & $10 / 54(18.5 \%)$ & $X(1)=0.50, p=0.580$ \\
\hline Chronic Kidney Disease & $37 / 200(18.5 \%)$ & 13/54 (24.1\%) & $X(1)=0.84, p=0.440$ \\
\hline Chronic liver disease & $6 / 200(3.00 \%)$ & 0/54 (0.00\%) & $X(1)=1.66, p=0.347$ \\
\hline
\end{tabular}

\section{DISCUSSION}

Of the 254 cases studied, $78.7 \%$ live in the household / with families, $15.4 \%$ in Nursing homes, $3.15 \%$ in host families and $2.75 \%$ in NICIC. In the social charter of 2014, there are 18104 elderly people residing in nursing homes, that is, $3.89 \%$ and 775 (0.04\%) elderly people living in host families ${ }^{2,19}$. Thus, the question is whether there are older people in these two institutions in our area of study or if these are the elderly who are most hospitalized.

The age and gender distribution of this sample is representative of the Portuguese population over 65 years of age, in which $57.9 \%$ are women and $42.1 \%$ are men, and there are no significant differences between the different origins? ${ }^{2}$. Of the study sample, $49.7 \%$ of the patients were illiterate or had less than 4 years of schooling, $49.7 \%$ had completed the 1 st cycle, $4 \%$ had a second cycle, $2 \%$ had a 3rd cycle, $0.70 \%$ secondary education and $2.7 \%$ higher education. These data are in line with national figures ${ }^{2}$. Since gender, age and schooling are similar to national values, the results of this study can probably be extrapolated to the Portuguese population.

Only 5.55\% (3/54) of others centres' patients are autonomous, which contrasts with the $47.0 \%$ (94/200) of the families' patients. This discrepancy of values can possibly be attributed to the fact that the elderly are more dependent more often hospitalized or our sample of elderly residents in others centres are effectively more dependent ${ }^{15}$. Patients from the home are more independent / slightly dependent, while those coming from others centres are more totally dependent, which is in agreement with other studies ${ }^{15}$. Despite this there are no significant differences in the number of comorbidities. But the number of comorbidities in this sample was high, all patients had at least a comorbidity with a maximum of 16 and a mean of 6.76 (SD=2.8). These numbers are especially important since the number of comorbidities is associated with the risk of hospitalization ${ }^{16}$. In addition, the Charslon index shows the relevance of comorbidities in the 
Table 3. Percentage of patients with or without PIM and PPO.

\begin{tabular}{|l|c|c|c|}
\hline \multicolumn{1}{|l|}{} & Families & Others centres & Comparation \\
\hline Total number of drugs prescribed & $7.63(\mathrm{SD}=3.6)$ & $7.91(\mathrm{SD}=3.4)$ & $\mathrm{t}(252)=0.66, \mathrm{p}=0.610$ \\
\hline Potentially Inappropriate Medications (PIM) & $1.05(\mathrm{SD}=0.9)$ & $2.19(\mathrm{SD}=1.2)$ & $\underline{\mathrm{t}(252)=5.85, \mathrm{p}<0.001}$ \\
\hline Number & $37 / 131(28.2 \%)$ & $20 / 53(37.7 \%)$ & $\mathrm{X}(1)=1.73, \mathrm{p}=0.217$ \\
\hline PIM suspended & & \\
\hline Potential Prescribing Omissions (PP0) & $0.70(\mathrm{SD}=0.78)$ & $1.17(\mathrm{SD}=0.97)$ & $\underline{\mathrm{t}(252)=3.71, p<0.001}$ \\
\hline Number & $24 / 107(22.4 \%)$ & $4 / 39(10.3 \%)$ & $\mathrm{X}(1)=2.31, \mathrm{p}=0.156$ \\
\hline PPO introduced & \multicolumn{2}{|c|}{ Statistically significant differences are underlined. }
\end{tabular}

Table 4. Duration of hospitalization, rehospitalization, intercurrence and death according to provenance.

\begin{tabular}{|l|c|c|c|}
\hline & Families & Others centres & Comparation \\
\hline Duration of hospitalization (days) & $10,4(\mathrm{SD}=7,9)$ & $11.7(\mathrm{SD}=10.2)$ & $\mathrm{t}(252)=6.9, \mathrm{p}=0.301$ \\
\hline Rehospitalization & $5 / 200(2.50 \%)$ & $5 / 54(9.26 \%)$ & $\underline{X(1)=5.14, p=0.039}$ \\
\hline Previous hospitalizations (<12 months) & $65 / 200(32.5 \%)$ & $25 / 54(46.3 \%)$ & $X(1)=3.54, p=0.077$ \\
\hline Intercurrences & $55 / 200(27.5 \%)$ & $32 / 54(59.3 \%)$ & $\underline{X(1)=19.0, p<0.001}$ \\
\hline Death up to 6 months after discharge & $24 / 200(12.0 \%)$ & $19 / 54(35.2 \%)$ & $\underline{X(1)=16.3, p<0.001}$ \\
\hline
\end{tabular}

prognosis of patients ${ }^{9}$. Since patients from other centers had a significantly higher Charlson index.

However there are differences regarding the type of comorbidities, others centres' patients have more neurological pathologies, which is in agreement with other studies. Some studies proven that neurological pathologies were associated with longer hospitalizations and higher mortality ${ }^{17}$. The hospitalization led to a significant worsening of the degree of dependence that is in agreement with other studies ${ }^{17}$.

Since the number of comorbidities leads to hospitalization, and hospitalization aggravates dependence, once again the importance of prevention, especially in a time when health care costs are so much talked about. Hypothetically, preventing comorbidities decreases the number of hospitalizations, so the direct costs associated with it and the indirect ones, associated with a higher degree of dependence after discharge.

The risks of polymedication and pharmacological interactions, especially in the elderly, are numerous and well known, especially with regard to the risk of hospitalization, morbidity and mortality ${ }^{18}$. In this study, $81.9 \%$ of patients were polymedicated, values much higher than those reported in other studies (20-75\%) and only $1.18 \%$ of patients had no chronic medications ${ }^{19}$. There are no significant differences in the number of drugs prescribed between the different origins.
In spite of this patients coming from others centres have significantly more PIM and PPO which is in agreement with other studies ${ }^{19}$. But it is worrying as more and more elderly people are institutionalized and the adverse effects and consequences of PIM and PPO are known and influence health status in a significant way ${ }^{5,18,20}$. Although other centres' elderly had more PIM and PPO, there were no statistically significant differences between the number of suspended PIMs or PPOs introduced.

The most prescribed PIM were benzodiazepines, antipsychotics and PPIs.

Patients residing in others centres are at greater risk of being medicated with psychotropic medication, both antipsychotics and benzodiazepines, many of them PIM ${ }^{16,21}$.

Benzodiazepines are associated with physical dependence, anterograde amnesia and risk of falls ${ }^{16,21}$. Antipsychotics (other than quetiapine and clozapine) are associated with increased risk of stroke, extrapyramidal effects and mortality ${ }^{16,21}$ Chronic use of PPIs is associated with an increased risk of pneumonia, enteric infections eg $C$. difficile and spontaneous bacterial peritonitis due to acid suppression ${ }^{22,23}$.

The most common PPO were anti-pneumococcal vaccine, anti-resorptive therapy and vitamin D. According to the clinical guideline standard vaccination against $\mathrm{S}$. pneumoniae infections is recommended in immunocompetent patients 
with chronic heart, liver, renal or respiratory disease, pretransplantation of organ or donation of bone marrow, diabetes mellitus and in case of cerebrospinal fluid fistulas or cochlear implants. In immunocompromised patients it is recommended for splenic dysfunction, primary immunodeficiency, HIV infection, transplant recipients, active neoplastic disease and iatrogenic immunosuppression ${ }^{12}$. Anti-resorptive therapy is recommended in bone densitometry patients at home osteoporosis and frailty patients regardless of the value of densitometry ${ }^{24}$. Vitamin $\mathrm{D}$ should be routinely given to institutionalized elderly people because they have low intakes, low sun exposure, and low cutaneous synthesis ${ }^{25}$. Patients from other centres are more readmitted, as proven in other studies ${ }^{16}$. Patients from others centres had significantly more complications during hospitalization. Also in relation to death in less than 6 months after discharge there are statistically significant differences, there were more deaths in patients from others centres (35.2\%), while patients from families died significantly less (12.0\%). A model identified the independent risk factors for mortality at 1 year after admission of the elderly that varied from 28 to $33 \%$ : male; number of BADLs dependent on discharge; congestive heart failure; cancer; creatinine level greater than $3.0 \mathrm{mg} / \mathrm{dL}$ and low albumin level. Despite taking into account the destination after the discharge, this study did not consider the provenance of the cases, which could bring significant results ${ }^{26}$. Other factors may be associated with higher post-discharge mortality in patients coming from others centres, such as nutritional status, as several studies have shown that there is better nutrition among the elderly living with their families ${ }^{27}$. Finally, several studies prove that the elderly prefer to be cared by relatives ${ }^{3}$, and institutionalized patients have a worse perception of their quality of life ${ }^{14}$.

\section{CONCLUSION}

In a world that, for cultural, economic and social reasons, the caregivers of the elderly are increasingly "employees" and not family. The association of the origin, here proven, with PIM, PPO, intercurrences during hospitalization, rehospitalization and death becomes even more relevant.

Older people prefer to be cared by family members, being in their family environment gives them quality of care and, by decreasing drug costs, hospitalization and general health, reduces expenses. It is the turning point in the care provided to the elderly in which more training is needed for the "employees", or more support for the family so they can become the caregivers again.

\section{BIBLIOGRAPHY}

1. Núcleo de Estudos de Geriatria da Sociedade Portuguesa de Medicina Interna. Avaliação Geriátrica Global "A pedra angular dos Cuidados ao Idoso". Diponible en: https://www.spmi.pt/docs_nucleos/GERMl_36.pdf

2. I.P. INE. Censos 2011 - Resultados Definitivos. Instituto Nacional de Estatística, Lisboa - Portugal. 2011. 10-12. Disponible en: https://censos.ine.pt > ngt_server > attachfileu

3. Higginson IJ et al. Social and clinical determinants of preferences and their achievement at the end of life: prospective cohort study of older adults receiving palliative care in three countries. BMC Geriatr. 2017;17(1):271.

4. O'Mahony D et al. STOPP/START criteria for potentially inappropriate prescribing in older people: version 2. Age Ageing. 2015; 44(2):213-8.

5. Scott I, Jayathissa S. Quality of drug prescribing in older patients: is there a problem and can we improve it? Intern Med J. 2010; 40:7-18.

6. O'Connor MN et al. Prevention of Hospital-Acquired Adverse Drug Reactions in Older People Using Screening Tool of Older Persons' Prescriptions and Screening Tool to Alert to Right Treatment Criteria: A Cluster Randomized Controlled Trial. J Am Geriatr Soc. 2016;64(8):1558-66.

7. Gallagher PF, O'Connor MN, O'Mahony D. Prevention of potentially inappropriate prescribing for elderly patients: a randomized controlled trial using STOPP/START criteria. Clin Pharmacol Ther. 2011;89:845-54.

8. Hovstadius B, Petersson G. Factors leading to excessive polypharmacy. Clinics in geriatric medicine. 2012;28(2):159-72.

9. Charlson ME, Pompei P, Ales KL, et al. A new method of classifying prognostic comorbidity in longitudinal studies: development and validation. J Chronic Dis. 1987;40:373-83.

10. Kirchhof P. et al. 2016 ESC Guidelines for the management of atrial fibrillation developed in collaboration with EACTS. European Heart Journal. 2016. 37(38), 2893-2962.

11. Lanza FL, Chan FK, Quigley EM Guidelines for prevention of NSAID-related ulcer complications. Am J Gastroenterol. 2009;104(3):728-38.

12. DGS. Vacinação contra infeções por Streptococcus pneumoniae de grupos com risco acrescido para doença invasiva pneumocócica (DIP). Adultos ( $\geq 18$ anos de idade). Norma n011/2015 de 23/06/2015 atualizada a 06/11/2015.

13. DGS. Deteção Precoce e Intervenção Breve no Consumo Excessivo de Álcool. Norma n030/2012 de 28/12/2012 atualizada a 18/12/2014

14. Lobo AJS, Santos L, Gomes S. Level of dependency and quality of life of elderly. Rev Bras. Enferm. 2014: 67(6).

15. Salanitro AH et al. Symptom Burden Predicts Hospitalization Independent of Comorbidity in Community-Dwelling Older Adults. J Am Geriatr Soc. 2012; 60(9): 1632-1637.

16. Czira ME et al., Association between neurological disorders, functioning, and mortality in the elderly. Acta Neurol. 2014. 130 (5): 283-91.

17. J. Boyd CM1, Xue QL, Guralnik JM, Fried LP. Hospitalization and development of dependence in activities of daily living in a cohort of disabled older women: the Women's Health and Aging Study I. Gerontol. A Biol Sci Med Sci.2005. 60 (7): 88893.

18. Maher RL, Hanlon J, and Hajjar ER: Clinical consequences of polypharmacy in elderly. Expert Opin Drug Saf.2014; 13: 57-65

19. M.M. Moraes, A. Matias, M.A. Soares, J. Gorjão C. Potentially inappropriate medicines use, by STOPP/START criteria, in a group of old patients admitted to a Portuguese hospital. European Geriatric Medicine. 2013; 4(1): S195

20. Lesende M. et al. Potentiality of STOPP/START criteria used in primary care to effectively change inappropriate prescribing in elderly patients. European Geriatric Medicine. 2013; 4(5): 293-298

21. Uzun S1, Kozumplik 0, Jakovljevi囚 M, Sedi囚 B. Side effects of treatment with benzodiazepines. Psychiatr Danub. 2010;22(1):90-3.

22. Laheij RJF, Sturkenboom MCJM, Hassing RJ, et al: Risk of community-acquired pneumonia and use of gastric acid-suppression drugs. JAMA. 2004; 292: 19551960.

23. Leonard J, Marshall JK, and Moayyedi P: Systematic review of the risk of enteric infections in patients taking acid suppression. Am J Gastroenterol. 2007; 102: 2047-2056

24. Sociedade Portuguesa de Reumatologia (SPR) e pela Sociedade Portuguesa de Doenças Ósseas Metabólicas. Recomendações para o diagnóstico e terapêutica da Osteoporose. 2007. Disponible en: https://spreumatologia.pt/wp-content/ uploads/2019/12/18_recomenda_es_para_0_diagn_stico_e_terap_utica_da_ osteoporose file.pdf

25. Reid I.R., Bolland M.J., and Grey A.: Effects of vitamin D supplements of bone mineral density: a systematic review and meta-analysis. Lancet. 2014; 343:146155

26. Walter $\mathrm{LC}$ et al. Development and validation of a prognostic index for 1-year mortality in older adults after hospitalization. JAMA. 2001;285(23):2987-94

27. Kucukerdonmez O, Navruz Varli S, Koksal E. Comparison of Nutritional Status in the Elderly According to Living Situations. J Nutr Health Aging. 2017. 21(1):25-30. 